\title{
Evaluation of soil corrosivity and aquifer protective capacity using geoelectrical investigation in Bwari basement complex area, Abuja
}

\author{
A E Adeniji ${ }^{1, *}$, O V Omonona ${ }^{2}$, D N Obiora $^{1}$ and $\mathrm{J} \mathrm{U} \mathrm{Chukudebelu}^{1}$ \\ ${ }^{1}$ Department of Physics and Astronomy, University of Nigeria, Nsukka, Nigeria. \\ ${ }^{2}$ Department of Geology, University of Nigeria, Nsukka, Nigeria. \\ ${ }^{*}$ Corresponding author.e-mail: emmaabidec@yahoo.com
}

\begin{abstract}
Bwari is one of the six municipal area councils of the Federal Capital Territory (FCT), Abuja with its attendant growing population and infrastructural developments. Groundwater is the main source of water supply in the area, and urbanization and industrialization are the predominant contributors of contaminants to the hydrological systems. In order to guarantee a continuous supply of potable water, there is a need to investigate the vulnerability of the aquifers to contaminants emanating from domestic and industrial wastes. A total of 20 vertical electrical soundings using Schlumberger electrode array with a maximum half current electrodes separation of $300 \mathrm{~m}$ was employed. The results show that the area is characterized by 3-6 geoelectric subsurface layers. The measured overburden thickness ranges from 1.0 to $24.3 \mathrm{~m}$, with a mean value of $7.4 \mathrm{~m}$. The resistivity and longitudinal conductance of the overburden units range from 18 to $11,908 \Omega \mathrm{m}$ and 0.047 to 0.875 mhos, respectively. Areas considered as high corrosivity are the central parts with $\rho<180 \Omega \mathrm{m}$. The characteristic longitudinal unit conductance was used to classify the area into zones of good (0.7-4.49 mhos), moderate (0.2-0.69 mhos), weak (0.1$0.19 \mathrm{mhos})$, and poor $(<0.1)$ aquifer protective capacity. Zones characterized by materials of moderate to good protective capacity serve as sealing potential for the underlying hydrogeological system in the area. This study is aimed at delineating zones that are very prone to groundwater contamination from surface contaminants and subsurface soils that are corrosive to utility pipes buried underground. Hence the findings of this work will constitute part of the tools for groundwater development and management and structural/infrastructural development planning of the area.
\end{abstract}

\section{Introduction}

Groundwaters entails water existing beneath the earth surface and sustainable amount of groundwater is contained in geologic formation or part of geologic formation called aquifers. Prospecting for viable aquifers for groundwater supply has over the years been done or carried out using various means ranging from physical observations to surface- and subsurface-geophysical techniques (Todd and Mays
2005). Geophysical techniques detect differences of physical properties such as density, magnetism, elasticity, and electrical resistivity within the earth crust (Todd and Mays 2005). Geoelectrical methods (principally vertical electrical sounding) have been preferred in groundwater and environmental studies when compared to other geophysical survey techniques, since these methods provide portability of equipment, rapid measurement of electrical resistivity, and lesser ambiguity in interpretations of

Keywords. Aquifer protective capacity; Bwari; longitudinal unit conductance; corrosion; vertical electric sounding. 
results when compared to other methods and also these methods do not have any destructive effect on the environment (Todd and Mays 2005). The electrical resistivity techniques involve sending direct currents into the soil/rock via electrodes (current electrodes) and measuring the resulting potential difference via potential electrodes. Different standard electrode arrangements or arrays have been developed; however, Werner and Schlumberger arrays are the most widely used. The measured current and potential difference is used in estimating the apparent resistivity of soils and rock over unspecified depths or positions. The resistivity of soils and rocks depends largely on rock properties such as porosity, permeability, ionic content of the pore fluids, and clay mineralization and these vary with space and time. It is this variation in the rock resistivity (anomalies) as a function of the rock properties that is being targeted in electrical resistivity surveys to give a picture of the subsurface geologic materials and structures (Wightman et al. 2003; Oseji 2010).

Geophysical techniques have also been developed for groundwater contamination studies like mapping the extent of migration of contaminant plumes in aquifers and soils (Kelly 1976; Benson et al. 1997; Arristodemou and Thomas-Betts 2000; Adepelumi et al. 2001; Naudet et al. 2004) and in recent years, have been used to delineate areas that may be susceptible to contamination should any occur (Braga et al. 2006; Mogaji et al. 2007; Abiola et al. 2009; Atakpo and Ayolabi 2009). Because of the growing population of Abuja, more wastes, which are potential groundwater contaminants are being generated by the increasing population. So, in this regard, our main aim was to map or locate the zones that were non-corrosive to bury utilities/pipes and also to delineate areas that have good protection for the underlying aquiferous units.

\section{Geology of the study area}

The study area is located between latitudes $9^{\circ} 15^{\prime} 27^{\prime \prime}$ and $9^{\circ} 17^{\prime} 51^{\prime \prime} \mathrm{N}$ and longitudes $7^{\circ} 19^{\prime} 39^{\prime \prime}$ and $7^{\circ} 24^{\prime} 9^{\prime \prime} \mathrm{E}$ as shown in figure 1 . It covers an approximate area of about $40 \mathrm{~km}^{2}$. The area is underlain by migmatite-gneiss complex and granitoids (FSN 1978; Rahaman 1989). The rock types observed as outcrops are granites and migmatitie gneiss. The granites range in texture from medium to coarse grained, and are grey-coloured, massive and homogenous. Migmatite gneiss in the area is characterized by medium to upper amphibolitesfacies. The geological map of Abuja, which shows the various rock types underlying the area is presented in figure 2. Hydrogeologically, the area can be divided into two units namely: the aquiferous zone within the weathered overburden overlying the fresh basement rocks and the aquiferious zone within the intense fracture joint system in the partially weathered basement.

\section{Materials and methods}

In this research work, electrical resistivity survey was used, 20 vertical electrical soundings (VES) were carried out, and the Allied Ohmega tetrameter and its accessories were used. The conventional Schlumberger array pattern, with half electrode spacing $(\mathrm{AB} / 2)$ varying from $1 \mathrm{~m}$ to a maximum of $150 \mathrm{~m}$, was adopted. The apparent resistivity was computed using the equation:

$$
\rho_{a}=\pi\left(\frac{a^{2}}{b}-\frac{b}{4}\right) \frac{\Delta V}{I},
$$

where $\rho_{a}$ is apparent resistivity, $\pi$ is $\frac{22}{7}, G=$ $\pi\left(a^{2} / b-b / 4\right)$ is geometrical factor, and $\Delta V / I=$ $R$ is the resistance.

The apparent resistivity values obtained from equation (1) were plotted on bi-log graph against the half current electrode separation spacing. From these plots, qualitative deductions, such as the resistivity of the first or top layer, the depth of each layer, and the curve signatures or types were made. The initial quantitative interpretations were made using partial curve matching technique, in which the field curves produced or generated were matched segment by segment with the appropriate master curves and auxiliary curves.

The resistivities and thicknesses of the various layers were improved upon by employing an automatic iterative computer program following the main ideas of Zohdy and Martin (1993). The WINRESIST computer software was employed for carrying out the iteration and inversion processes. The iteration process was conducted for each sounding station until the root mean square (RMS) error of lower than $5 \%$ was obtained.

The total longitudinal conductance $\left(S_{T}\right)$ of the overburden unit at each vertical electrical sounding station was obtained from the mathematical relation (Zohdy et al. 1974):

$$
S_{T}=\sum_{i=1}^{n} \frac{h_{i}}{\rho_{i}}
$$

where $S_{T}=$ total longitudinal conductance of the overburden, $\rho_{i}=$ layer resistivity, $h_{i}=$ layer thickness, and $n=$ number of layers and were used to characterize the aquifer protective capacity of the area. 


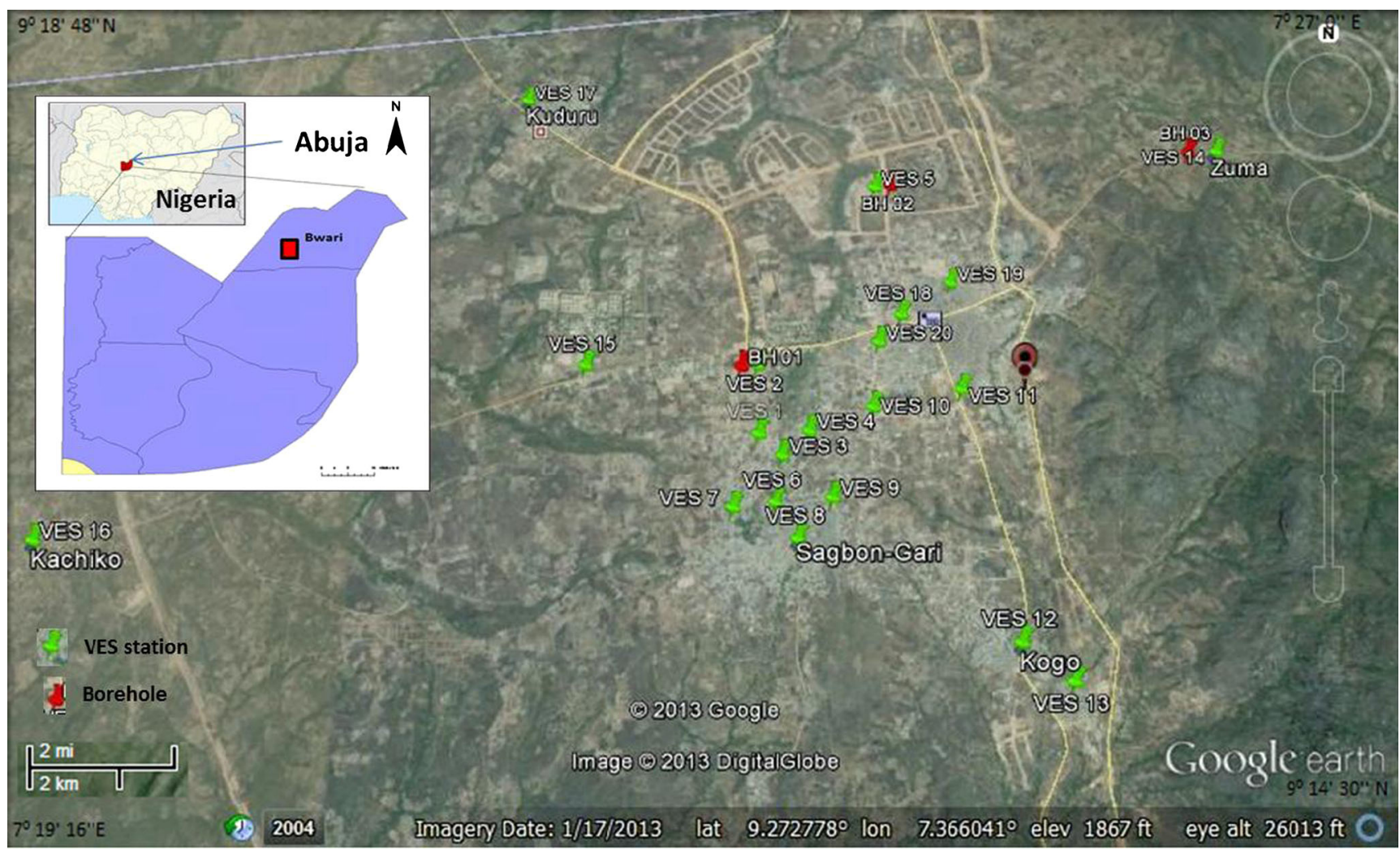

Figure 1. Google map of Bwari area, showing the VES points and borehole locations with the map of Nigeria and Abuja as insets.

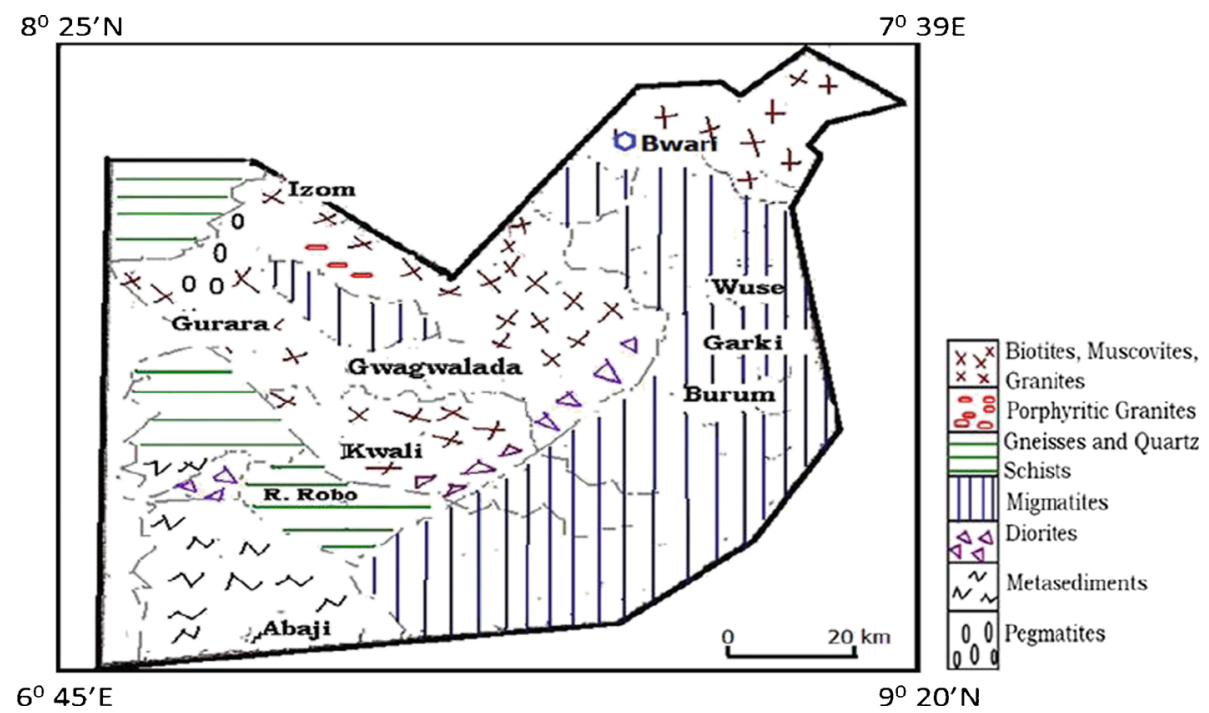

Figure 2. Geological map of Abuja (adapted from Dikedi 2012).

\section{Results and discussion}

\subsection{Geoelectric sections}

The summary ofthe results of the 20 vertical electrical soundings is presented in table 1. From the table, the resistivities of the first to fifth layers range from 44 to $1177 \Omega \mathrm{m}, 18$ to $11,908 \Omega \mathrm{m}$, 32 to $13,242 \Omega \mathrm{m}, 16$ to $92,805 \Omega \mathrm{m}$ and 234 to $5338 \Omega \mathrm{m}$, respectively. The thicknesses of the top layer to the bottom layer vary from $1.0-6.6 \mathrm{~m}$, $0.2-52.2 \mathrm{~m}, 1.0-63.7 \mathrm{~m}$ and $6.2-25.6 \mathrm{~m}$, respectively. The longitudinal conductance of the overburden units estimated from the resistivities and 
Table 1. Layers' resistivity, thicknesses, curve types and longitudinal conductance.

\begin{tabular}{|c|c|c|c|c|c|c|c|c|c|c|c|c|c|}
\hline \multirow{2}{*}{$\begin{array}{l}\text { VES } \\
\text { station }\end{array}$} & \multicolumn{6}{|c|}{ Layer resistivity (ohms) } & \multicolumn{5}{|c|}{ Layer thickness $(\mathrm{m})^{+}$} & \multirow[b]{2}{*}{ Curve type } & \multirow{2}{*}{$\begin{array}{c}\text { Longitudinal } \\
\text { conductance } \\
\text { (mhos) }\end{array}$} \\
\hline & $\rho_{1}$ & $\rho_{2}$ & $\rho_{3}$ & $\rho_{4}$ & $\rho_{5}$ & $\rho_{6}$ & $\overline{\mathrm{h}_{1}}$ & $\mathrm{~h}_{2}$ & $\mathrm{H}_{3}$ & $\mathrm{~h}_{4}$ & $\mathrm{~h}_{5}$ & & \\
\hline 1 & 442 & 5078 & 1982 & 62 & 234 & 21063 & 2.6 & 0.4 & 5.4 & 15.9 & 48.6 & AKHA & 0.472036 \\
\hline 2 & 44 & 2184 & 35 & 1668 & & & 2.1 & 0.8 & 25.5 & & & $\mathrm{KH}$ & 0.768650 \\
\hline 3 & 349 & 18 & 3357 & & & & 2.9 & 6.3 & & & & $\mathrm{H}$ & 0.354468 \\
\hline 4 & 214 & 62 & 1226 & & & & 5.6 & 52.2 & & & & $\mathrm{H}$ & 0.874761 \\
\hline 5 & 1177 & 155 & 7040 & & & & 6.6 & 37.5 & & & & $\mathrm{H}$ & 0.246919 \\
\hline 6 & 479 & 1047 & 1560 & 10618 & & & 1.3 & 6.5 & 18.6 & & & $\mathrm{AA}$ & 0.128304 \\
\hline 7 & 251 & 1066 & 2107 & 134 & 5338 & & 1.6 & 1.3 & 4.0 & 25.6 & & $\mathrm{AKH}$ & 0.199958 \\
\hline 8 & 344 & 274 & 5117 & 54677 & & & 1.1 & 11.9 & 1.0 & & & $\mathrm{HA}$ & 0.046919 \\
\hline 9 & 336 & 43 & 909 & & & & 1.1 & 5.8 & & & & $\mathrm{H}$ & 0.137220 \\
\hline 10 & 207 & 64 & 5941 & & & & 1.0 & 9.3 & & & & $\mathrm{H}$ & 0.148342 \\
\hline 11 & 110 & 59 & 3257 & 16 & 1232 & & 1.5 & 1.5 & 1.0 & 6.2 & & $\mathrm{HKH}$ & 0.421985 \\
\hline 12 & 455 & 482 & 111 & 6391 & & & 4.8 & 3.9 & 30.5 & & & $\mathrm{KH}$ & 0.293415 \\
\hline 13 & 438 & 11908 & 575 & 25454 & & & 1.5 & 0.7 & 63.7 & & & $\mathrm{KH}$ & 0.114288 \\
\hline 14 & 1109 & 357 & 6830 & 92805 & & & 1.4 & 22.6 & 1.9 & & & $\mathrm{HA}$ & 0.064846 \\
\hline 15 & 278 & 588 & 75 & 7075 & & & 1.6 & 1.4 & 54.9 & & & $\mathrm{KH}$ & 0.736265 \\
\hline 16 & 387 & 562 & 97 & 413 & & & 2.2 & 0.8 & 11.0 & & & $\mathrm{KH}$ & 0.120052 \\
\hline 17 & 212 & 314 & 77 & 17627 & & & 1.7 & 0.6 & 6.2 & & & $\mathrm{KH}$ & 0.090997 \\
\hline 18 & 95 & 101 & 13242 & & & & 3.5 & 4.1 & & & & $\mathrm{H}$ & 0.077594 \\
\hline 19 & 495 & 772 & 305 & 1391 & & & 3.5 & 0.9 & 15.9 & & & $\mathrm{KH}$ & 0.059770 \\
\hline 20 & 496 & 942 & 207 & 756 & & & 6.1 & 0.2 & 26.5 & & & $\mathrm{KH}$ & 0.140345 \\
\hline
\end{tabular}

${ }^{\#} \mathrm{VES}=$ vertical electrical sounding, ${ }^{*} \rho_{1}=$ first layer resistivity, $\rho_{2}=$ second layer resistivity, $\rho_{3}=$ third layer resistivity $\rho_{4}=$ fourth layer resistivity, $\rho_{5}=$ fifth layer resistivity, $\rho_{6}=$ sixth layer resistivity, ${ }^{+} \mathrm{h}_{1}=$ first layer thickness, $\mathrm{h}_{2}=$ second layer thickness, $\mathrm{h}_{3}=$ third layer thickness, $\mathrm{h}_{4}=$ fourth layer thickness, $\mathrm{h}_{5}=$ fifth layer thickness, $\mathrm{m}=$ meters.

thicknesses of the overburden units range from 0.0469 to 0.875 mhos. Eight transverses connecting the 20 VES points were covered and their subsurface geoelectric sections are presented in figure 3 . The lithology of each layer was inferred by comparing inverted resistivity with typical electrical resistivity of earth materials bearing in mind the surficial geology within the vicinity of the sounding station. VES at stations 2, 5 and 14 were carried out in the vicinity of existing boreholes. The lithology of the various layers in the boreholes was determined from washed core samples that were taken at specific intervals of depth. The inferred lithologies and thicknesses of the various layers from the subsurface geoelectric sections of these VES stations were compared with the lithologic logs of the boreholes located very close to them and it was revealed that they are very well correlated (figure 4). At VES 5, the VES reveals three subsurface geoelectric layers which correspond to the number of the subsurface layers described by the lithologic logs. Also, the inferred lithologies and thicknesses of the various subsurface layers from the VES correspond essentially with the lithologies and thicknesses of the various subsurface layers defined by the lithologic logs (figure 4). At VES 2 , the geoelectric section reveals the same number of subsurface layers as the lithologic log. The thicknesses of the subsurface layers described by the VES varied slightly from those of the lithologic log (figure 4) while at VES 14, four subsurface layers were defined by the VES and three layers by the lithologic log (figure 4 ). The 4th subsurface layer of the geoelectric section was inferred to be fresh basement rock which was not described by the lithologic log. According to Zhody et al. (1974), the 3rd layer of the lithologic log is characterized by two distinct resistivity values and these two units within the layer having different resistivities are seen as two distinct layers by the VES. The uncertainties involved in the estimates of resistivity and depth of the subsurface lithological layers include the problem of approximate equivalence between two multilayer sections attributed to the principle of suppression which causes errors in depth of contact estimation known as pseudoanistropy. Due to monotonic change in resistivity, where there is either an increase or decrease monotonically in the resistivity of the subsurface layers, the sounding curves of a 3-layer model (A and Q) and 4-layer model (AA and QQ), may resemble curves of a simple 2-layer model.

From figure 3, the geoelectric subsurface section ranges from 3 to 6 layers with the 4-layer as the dominant type. The 3-layer geoelectric section is characterized by $\mathrm{H}$ curve type (figure 5) and is generally made up of top loose soil, laterite/clay, and fresh basement rock from top to bottom with 

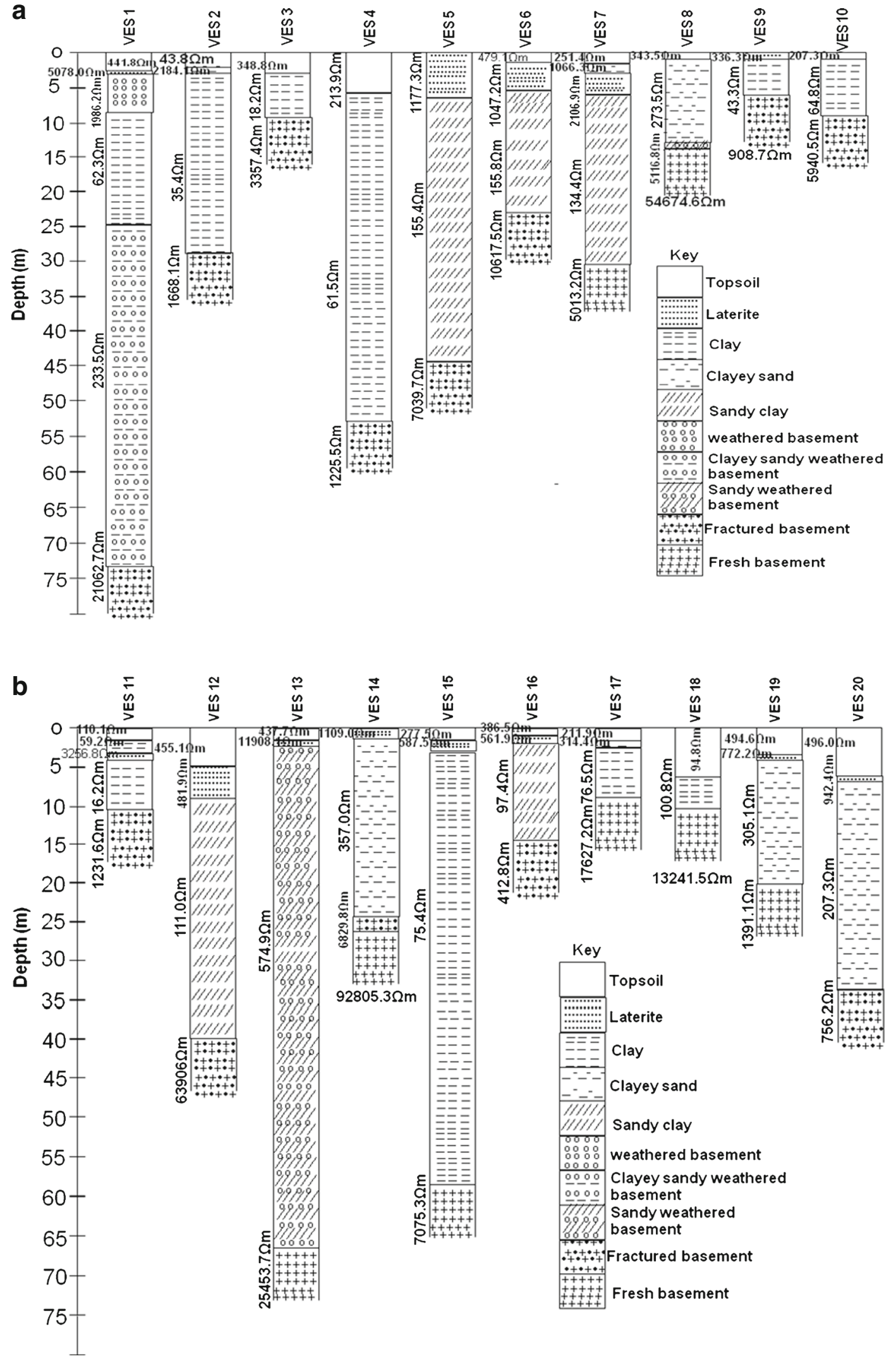

Figure 3. 1-D geoelectrical models for VES 1-20. 


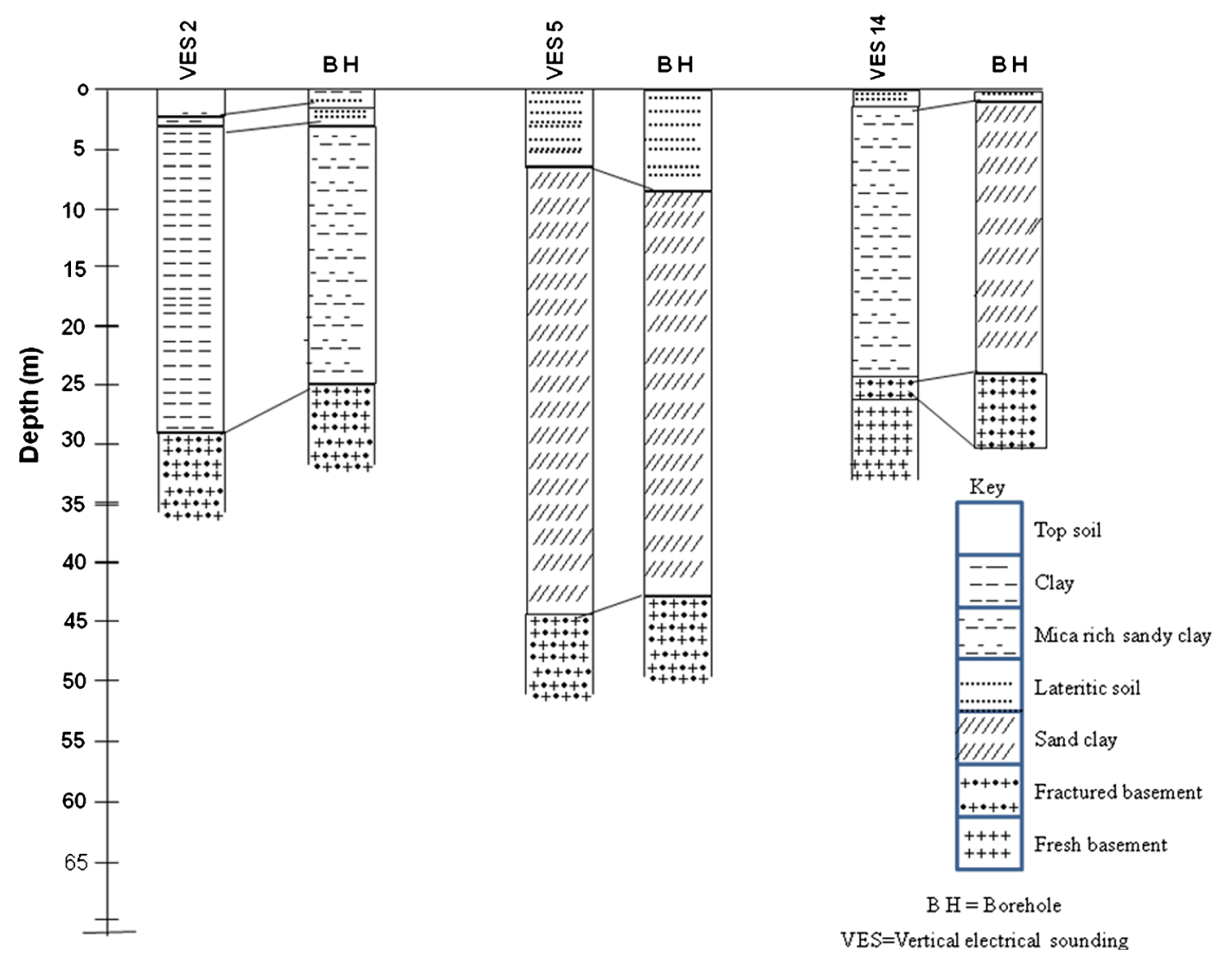

Figure 4. Correlation between geoelectric section and lithological log.

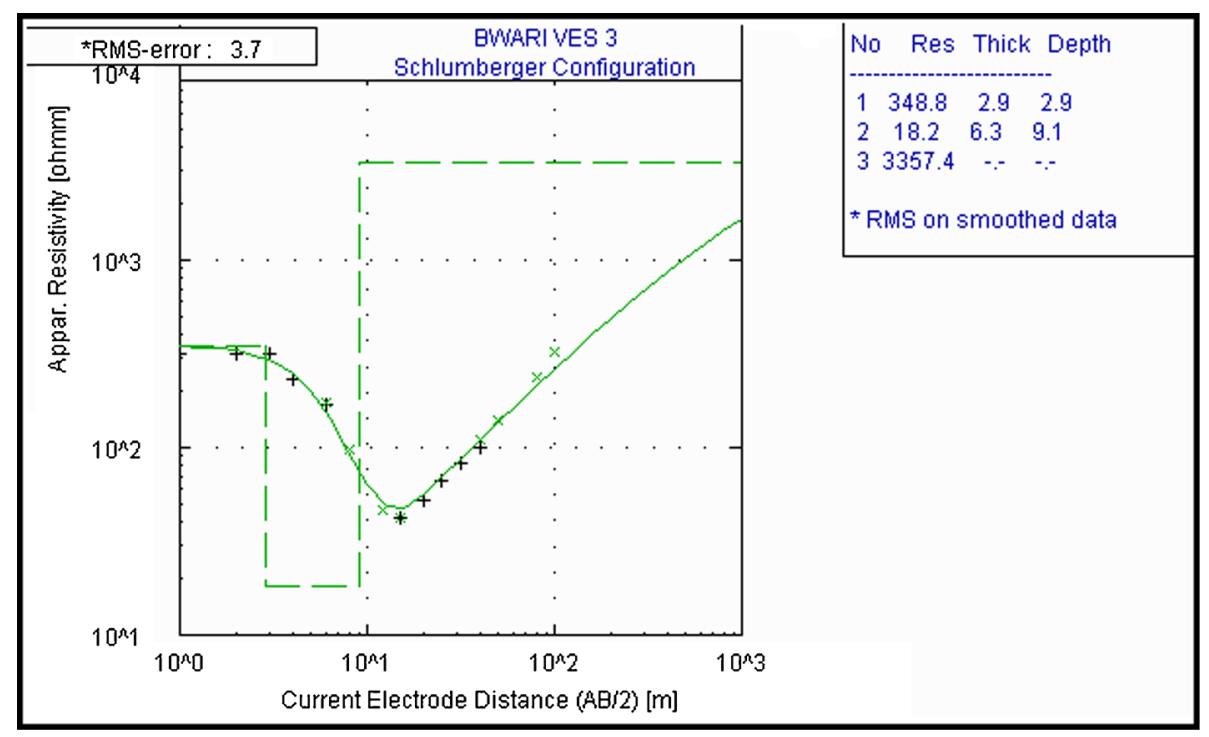

Figure 5. Typical H curve type.

variable thicknesses and resistivities. The 4-layer geoelectric section is characterized by $\mathrm{KH}, \mathrm{HA}$, and AA curve types (figures 6-8). The 5-layer geoelectric section is characterized by $\mathrm{AKH}$ and HKH curve types (figures 9 and 10). Curve types depict the relationships between lithological layers' resistivity (table 2). The occurrence of different curve types from place to place within an area shows high variability in the nature of the subsurface geological materials (Zohdy et al. 1974). The overburden thickness ranged from 1.0 to $24.3 \mathrm{~m}$ with a mean of $7.4 \mathrm{~m}$; thickest and thinnest 


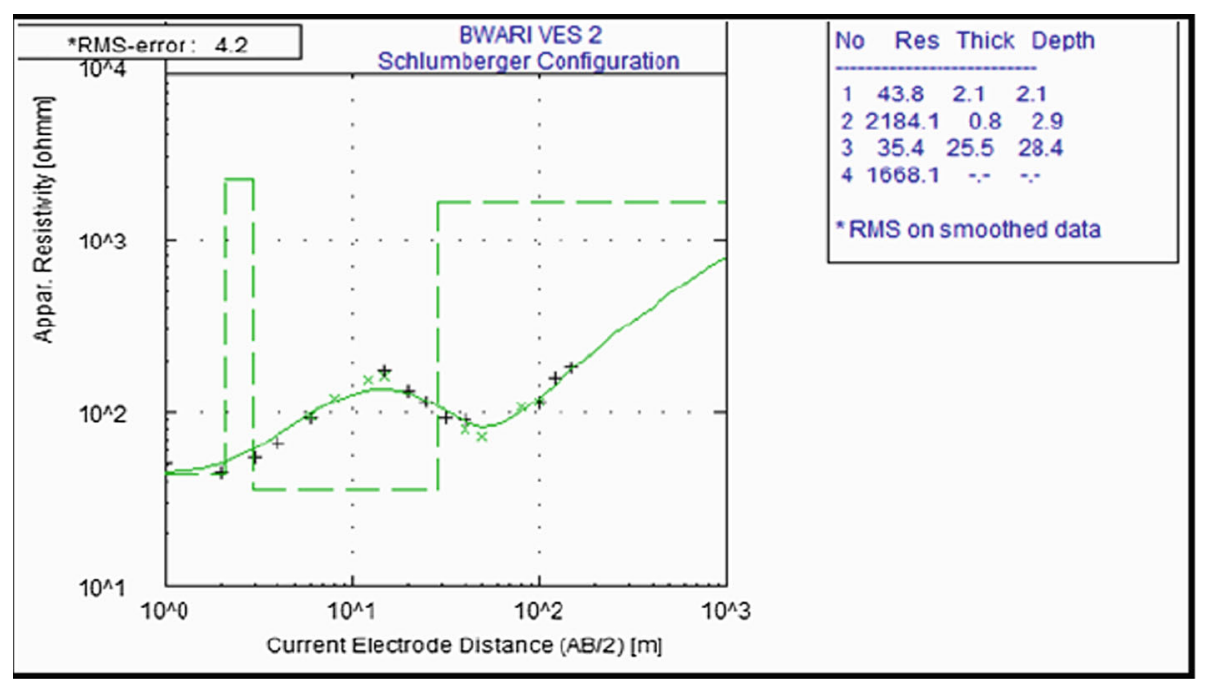

Figure 6. Typical KH curve type.

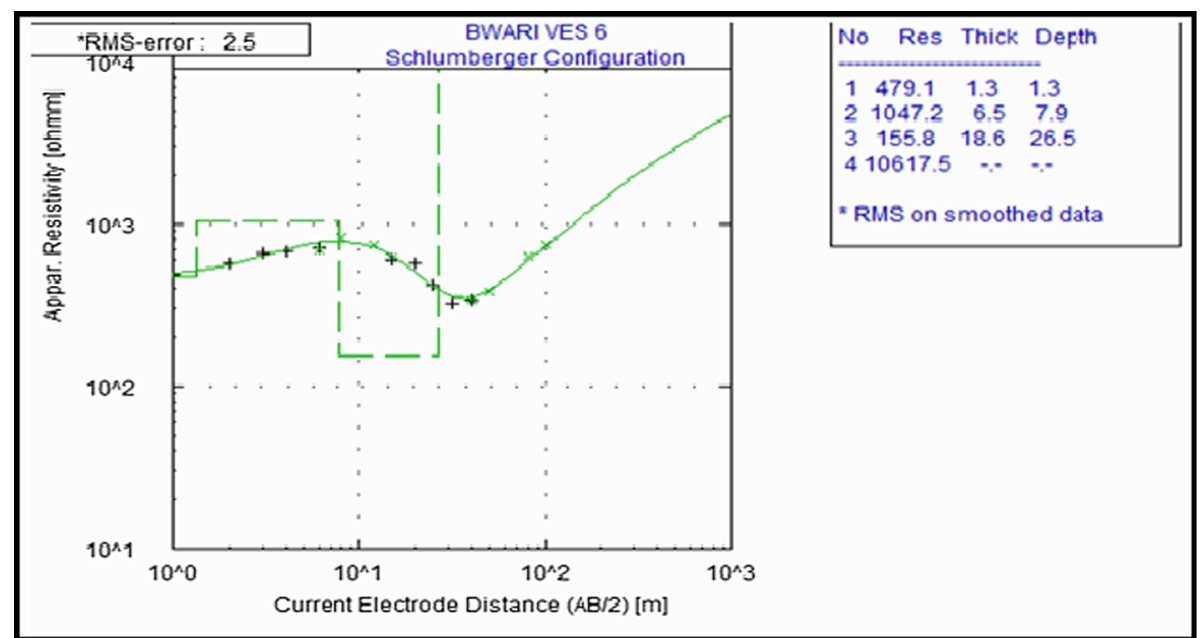

Figure 7. Typical AA curve type.

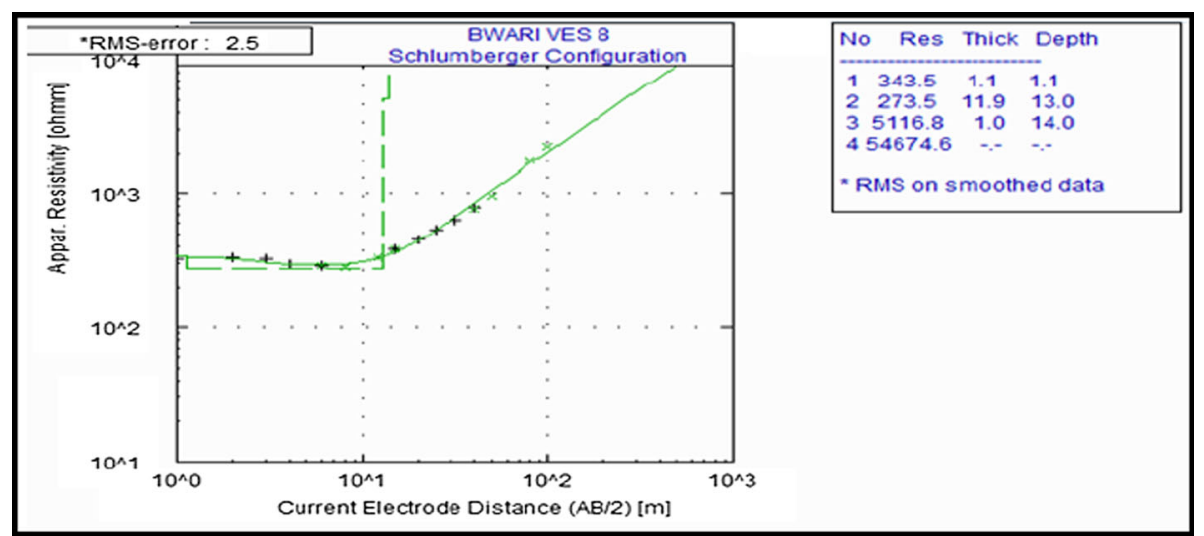

Figure 8. Typical HA curve type. 


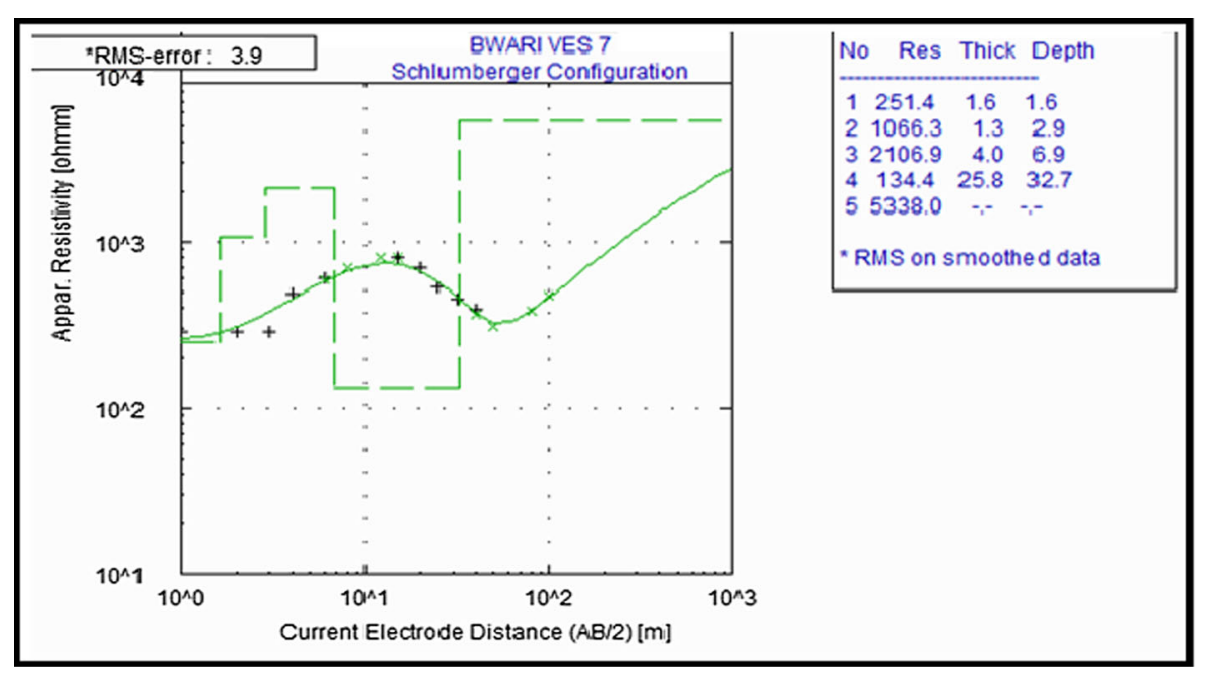

Figure 9. Typical AKH curve type.

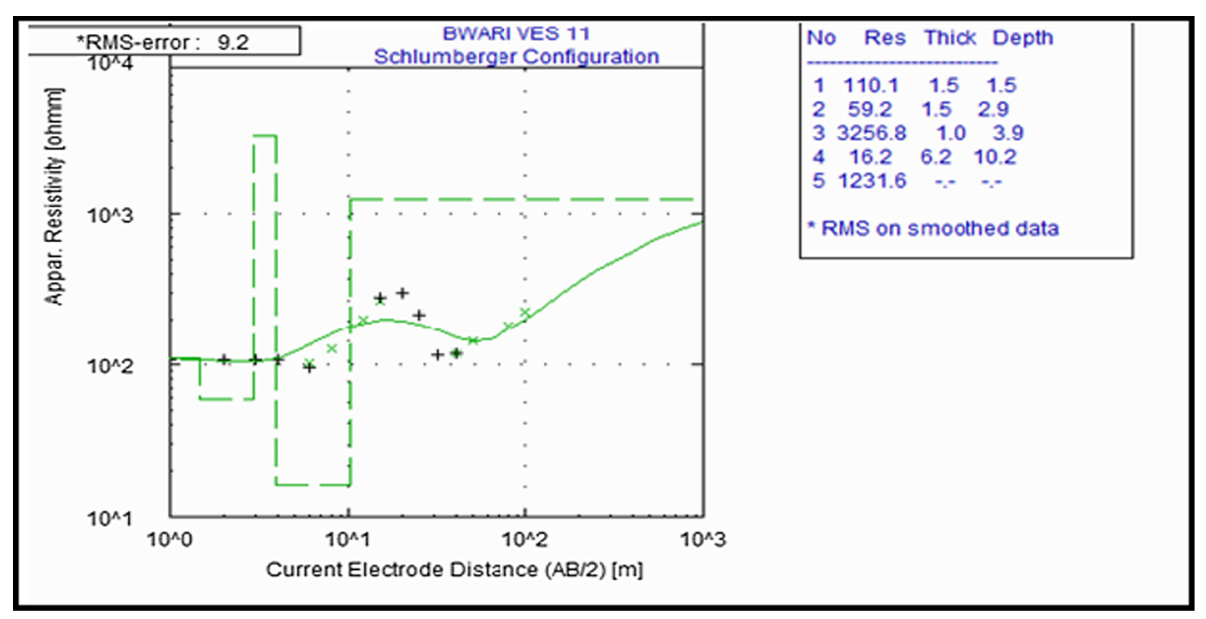

Figure 10. Typical HKH curve type.

Table 2. Classification of curve types.

\begin{tabular}{ll}
\hline Curve type & \multicolumn{1}{c}{$\begin{array}{c}\text { Layer's resistivity } \\
\text { relationship }\end{array}$} \\
\hline $\mathrm{H}$ & $\rho_{1}>\rho_{2}<\rho_{3}$ \\
$\mathrm{HA}$ & $\rho_{1}>\rho_{2}<\rho_{3}<\rho_{4}$ \\
$\mathrm{KH}$ & $\rho_{1}<\rho_{2}>\rho_{3}<\rho_{4}$ \\
$\mathrm{AA}$ & $\rho_{1}<\rho_{2}<\rho_{3}<\rho_{4}$ \\
$\mathrm{HKH}$ & $\rho_{1}>\rho_{2}<\rho_{3}>\rho_{4}<\rho_{5}$ \\
$\mathrm{AKH}$ & $\rho_{1}<\rho_{2}<\rho_{3}>\rho_{4}<\rho_{5}$ \\
$\mathrm{AKHA}$ & $\rho_{1}<\rho_{2}<\rho_{3}>\rho_{4}<\rho_{5}<\rho_{6}$ \\
\hline
\end{tabular}

Note: $\rho$ - resistivity.

overburden is observed around places such as Zuma and Bwari, respectively (figure 11).

\subsection{Evaluation of soil corrosivity}

Civil engineering construction works generally include laying of metallic pipes. Buried pipes are susceptible to corrosion and subsequent failure if the host soil medium is corrosive and aggressive (Akintorinwa and Abiola 2011). Topsoil constitutes the layer within which normal civil engineering foundations and utility pipes are buried. The thickness of this layer ranges from 1.0 to $6.6 \mathrm{~m}$ while the resistivity ranges from 44 to $1177 \Omega \mathrm{m}$ in the present study. The topsoil (first layer) resistitvity values obtained from the interpretations of the VES results were utilized in evaluating the corrosivity of the subsoils. Very high resistivity values $(>1000 \Omega \mathrm{m})$ and low resistivity values $(<40 \Omega \mathrm{m})$ are observed at the northeastern and central zones, respectively. Topsoil resistivity values were classified in terms of soil corrosion based on (Baeckmann and Schwenk 1975; Agunloye 1984; Oladapo et al. 2004) soil resistivity classification model (table 3). Topsoil resistivity values range from 44 to $1177 \Omega \mathrm{m}$, with a mean value of $415.41 \Omega \mathrm{m}$ and the topsoil corrosivity 


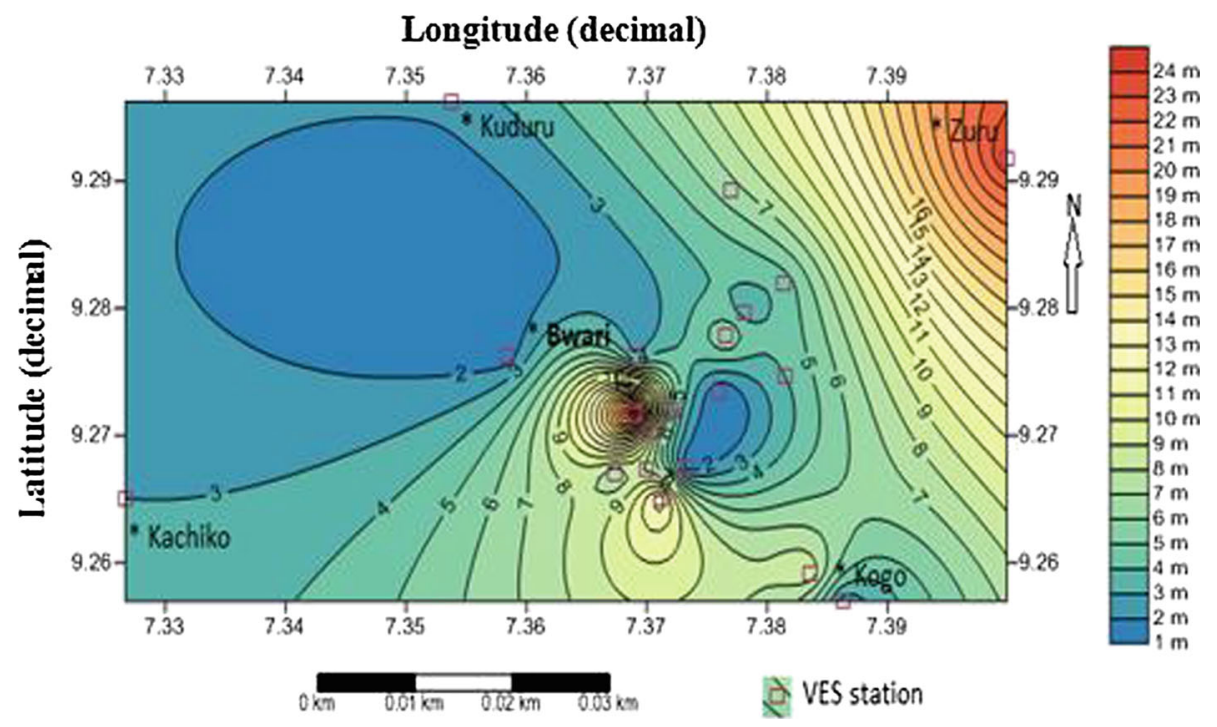

Figure 11. Overburden isopach map of Bwari basement area.

Table 3. Classification of soil resistivity in terms of corrosivity (based on Baeckmann and Schenwenk 1975; Agunloye 1984; Oladapo et al. 2004).

\begin{tabular}{ll}
\hline Soil resistivity $(\Omega \mathrm{m})$ & \multicolumn{1}{c}{ Soil corrosivity } \\
\hline$<10$ & Very strongly corrosive (VSC) \\
$10-60$ & Moderately corrosive (MC) \\
$60-180$ & Slightly corrosive (SC) \\
$>180$ & Practically noncorrosive (PNC) \\
\hline
\end{tabular}

varied from 'practically noncorrosive' to 'moderately corrosive'.

Part of the central area is considered to be of high corrosivity $(\rho \leq 180 \Omega \mathrm{m})$ while the remaining areas are of low corrosivity $(\rho \leq 180 \Omega \mathrm{m}$; figure 12$)$. Over $60 \%$ of the study area has relatively high topsoil resistivity values with low tendency for corrosivity. Only the sections around the central area where 'moderately' and 'slightly' corrosive topsoil are observed will metallic pipes/utility buried in them be susceptible to corrosion.

\subsection{Evaluation of aquifer protective capacity}

Aquifer protective capacity (APC) is the ability of the overburden unit to retard and filter percolating ground surface polluting fluid into the aquiferous unit. The second order geoelectric parameter, longitudinal conductance (Dar Zarrouk parameter) was evaluated from the primary/first order parameters (thickness and resistivity) of the geoelectric subsurface layers which were used in the classification of the APC of the area. Highly impervious materials such as clay and shale usually have high longitudinal conductance values (resulting from their low resistivity values) while pervious materials such as sand and gravels have low longitudinal conductance values (resulting from their high resistivity values). While high longitudinal conductance value corresponds to excellent and good APC, low longitudinal conductance values are associated with poor and weak APC.

Based on longitudinal conductance values, overburden units can be classified into excellent, very good, good, moderate, weak and poor aquifer protective capacity. Overburden units with longitudinal conductance value $>10$ mhos give an excellent APC, and longitudinal conductance values ranging from 5 to 10 mhos give rise to very good APC. Longitudinal conductance values in the range of $0.7-4.9$ mhos and 0.2-0.69 give rise to good and moderate APC ratings, respectively. Weak and poor APC ratings are defined by longitudinal conductance in the range of $0.1-0.19$ and $<0.1$, respectively.

Figure 13 presents the spatial distribution of the longitudinal conductance of the overburden units of the study area, with highest and lowest values around places such as Bwari and Zuma respectively. In order to categorize the aquifer protective capacity of the area, aquifer protective capacity rating model (after Henriet 1976; Oladapo et al. 2004; table 4) was employed. Four aquifer protective capacity zones, weak $0.1-0.19$, poor $<0.1$, moderate $0.2-0.69$ and good $0.7-4.49$ were delineated. The good and medium aquifer protective capacity zones coincide with zones of appreciable overburden thicknesses with clayey column and low resistivity while the weak and poor zones coincide with zones of shallow or thin overburden and high 


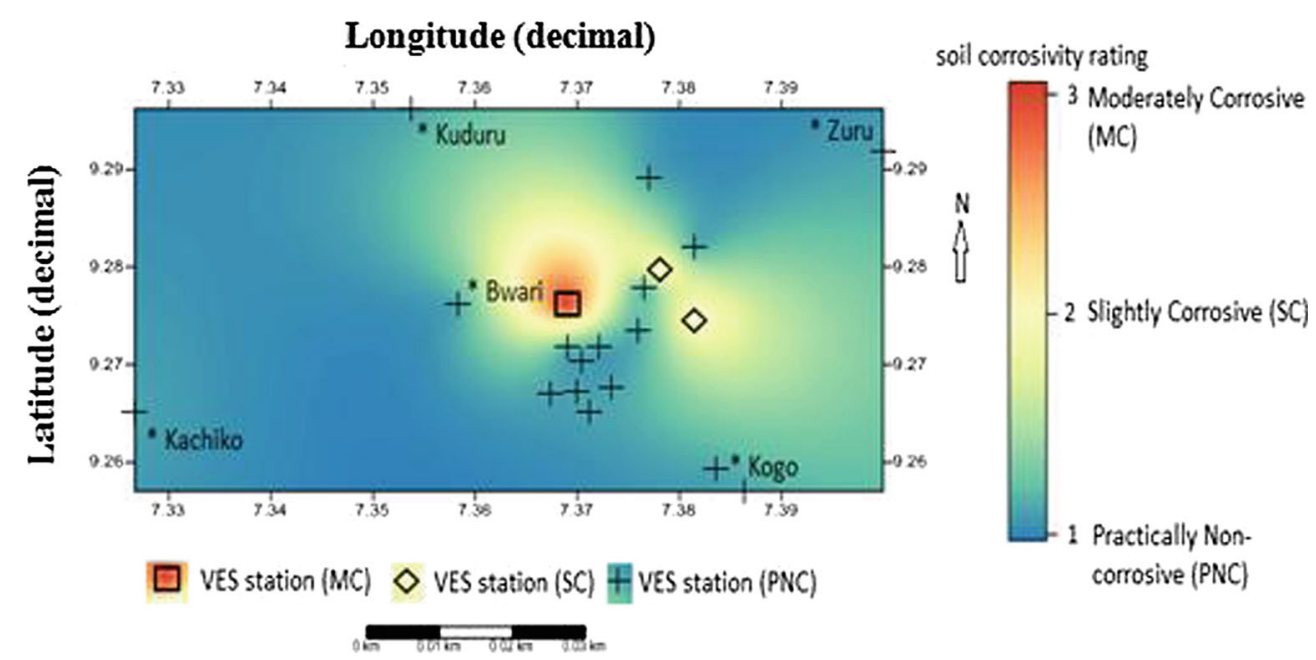

Figure 12. Soil corrosivity map of Bwari basement area.

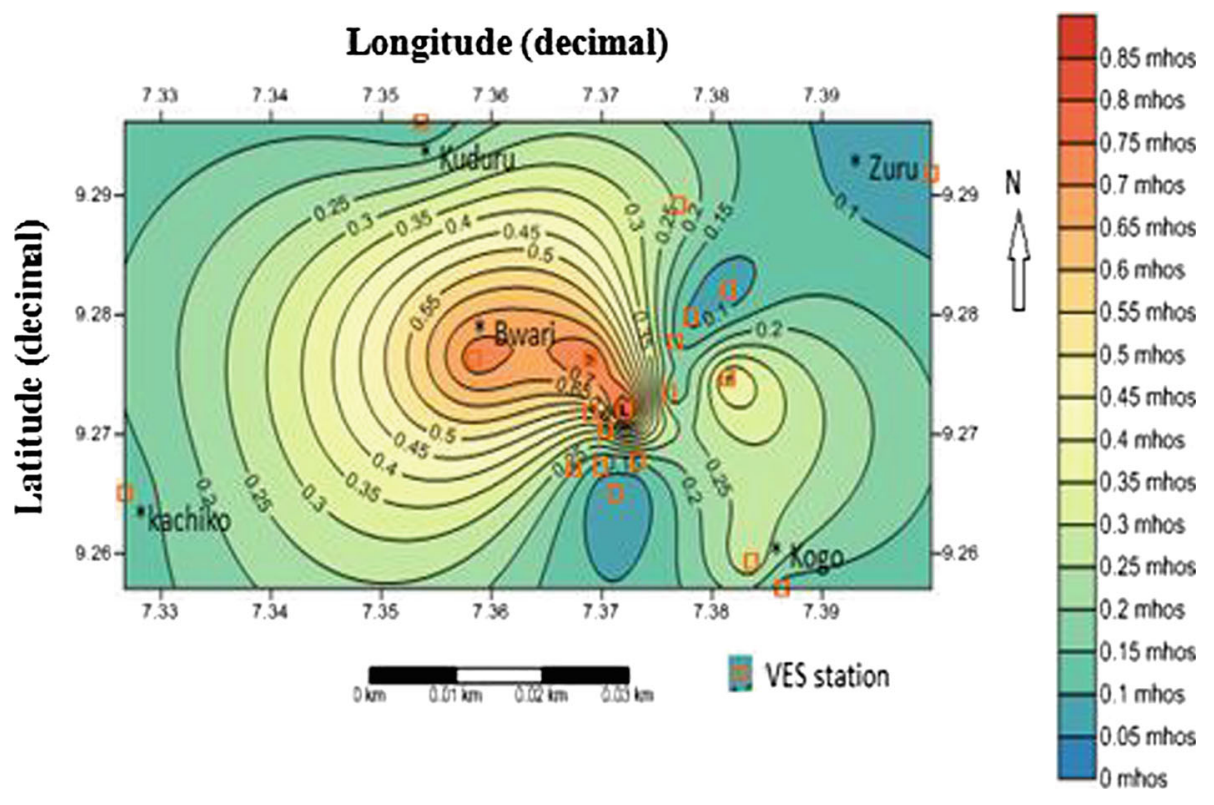

Figure 13. Spatial distribution of longitudinal conductance of the overburden units.

Table 4. Longitudinal conductance/aquifer protective capacity rating.

\begin{tabular}{ll}
\hline $\begin{array}{l}\text { Longitudinal } \\
\text { conductance (mhos) }\end{array}$ & $\begin{array}{c}\text { Aquifer protective } \\
\text { capacity rating }\end{array}$ \\
\hline$>10$ & Excellent \\
$5-10$ & Very good \\
$0.7-4.49$ & Good \\
$0.2-0.69$ & Moderate \\
$0.1-0.19$ & Weak \\
$<0.1$ & Poor \\
\hline
\end{tabular}

Source: Henriet (1976) and Oladpo et al. (2004).

electrical resistivity. The aquifer protective capacity map of the study area (figure 14) revealed that about $60 \%$ of the area covered by poor and weak aquifer protective capacity zones are vulnerable to surface contamination sources (leakage from underground petroleum storage tanks, infiltration of leachates from decomposing of open refuse dumps and diffuse pollution from agricultural activities) in the area. The good and moderate aquifer protective capacity zones which constitute $40 \%$ of the area have higher attenuation property on contaminated fluids so that in the face of contamination such zones are apparently safe.

\section{Conclusions}

Surface geoelectrical investigation has been applied to environmental study of Bwari basement complex 


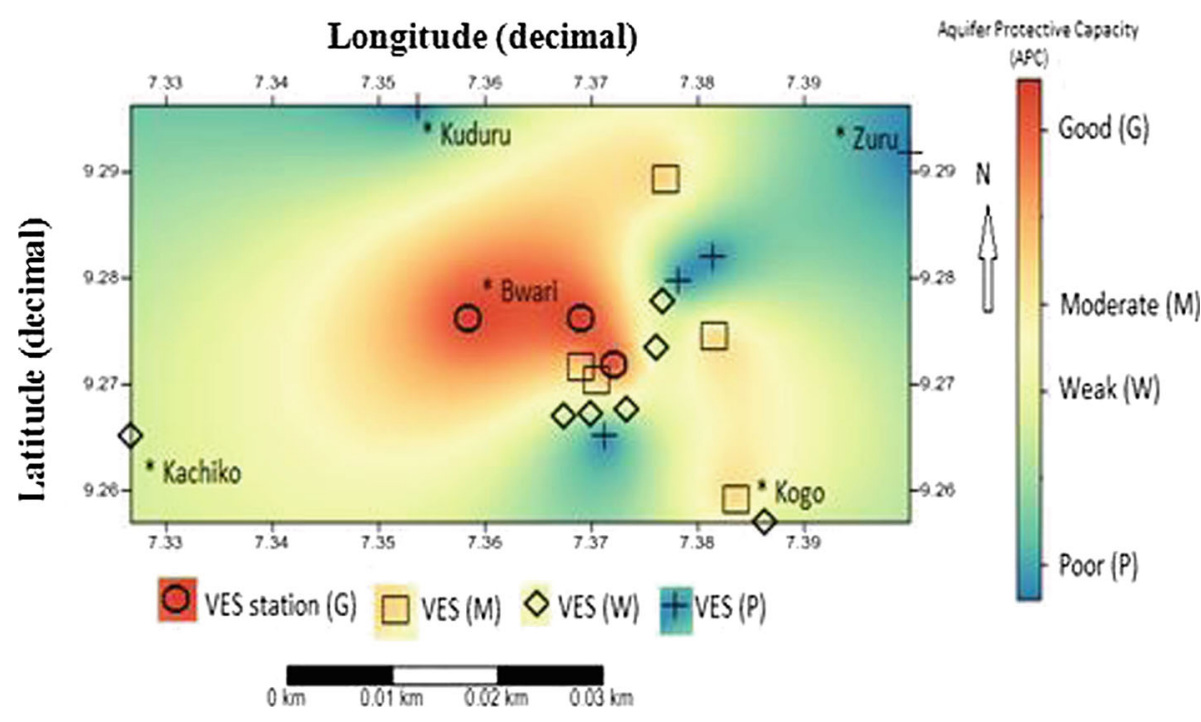

Figure 14. Aquifer protective capacity map of Bwari basement area.

area. The results revealed the efficiency of electrical resistivity surveys in delineating different zones of soil corrosivity of the topsoil units and the aquifer protective capacity of the overburden units.

The northern, southern, western and eastern parts of the study area with high resistivity $(\rho>180 \Omega \mathrm{m})$ topsoil are precisely noncorrosive. While a section of the central part of the study area contains corrosive topsoil with low resistivity $(\rho<180 \Omega \mathrm{m})$; metallic utilities/pipes, etc., required for reticulation works buried within the superficial layer in the area are susceptible to corrosion suggesting a significant contribution of clayey matrix in the layer.

Four distinct aquifer protective capacity zones were defined, namely poor, weak, moderate and good. The rating was based on longitudinal conductance values. Vertical electrical sounding stations, whose computed longitudinal conductance values range from 0.7 to 4.9 mhos, 0.2 to 0.69 mhos, 0.1 to 0.19 mhos and $<0.1$ mhos are respectively classified as good, moderate, weak and poor aquifer protective capacity zones. Poor and weak aquifer protective capacity zones are very vulnerable to contamination, while areas of moderate and good aquifer protective capacity zones are less vulnerable to contamination.

\section{Acknowledgement}

The authors wish to thank Mr. Enahoro Asije of Department of Geology, University of Nigeria, Nsukka, who assisted in the field data collection. Also, the authors wish to appreciate the critical reviews and comments of the anonymous reviewers that improved the manuscript.

\section{References}

Abiola O, Enikanselu P A and Oladapo M I 2009 Groundwater potential and aquifer protective capacity of overburden units in Ado-Ekiti, southwestern Nigeria; Int. J. Phys. Sci. 4(3) 120-132.

Adepelumi A A, Ako B D and Ajayi T R 2001 Groundwater contamination in the basement complex area of Ile-Ife southwestern Nigeria: A case study using the electricalresistivity geophysical method; Hydrogeol. J. 9 611-622.

Agunloye O 1984 Soil aggressivity along steel pipeline route at Ajaokuta southwestern Nigeria; J. Mining Geol. 21 97-101.

Akintorinwa O J and Abiola O 2011 Sub-soil evaluation for pre-foundation study using geophysical and geotechnical approach; J. Emerging Trends Eng. Appl. Sci. 2(5) 858-863.

Arristodemou E and Thomas-Betts A 2000 DC resistivity and induced polarization investigations at a waste disposal site and its environments; J. Appl. Geophys. 44 $275-302$.

Atakpo E A and Ayolabi E A 2009 Elevation of aquifer vulnerability and protective capacity in some oil producing communities of western Niger delta; Env. 29 310-317.

Baeckmann W V and Schwenk W 1975 Handbook of cathodic protection: The theory and practice of electrochemical corrosion protection technique; Surrey Protucullin Press.

Benson A K, Payne K L and Stubben M A 1997 Mapping groundwater contamination using de resistivity and VLF geophysical methods - a case study; Geophysics 62(1) 80-86.

Braga A O, Filho W M and Dourado J C 2006 Resistivity (DC) method applied to aquifer protection studies; Revista Brasileira Geofisica 24(4) 513-581.

Dikedi P N 2012 Geoelectric probe for groundwater in Giri Nigeria; Global J. Sci. Frontier Research Physics and Space 12(2.1) 43-54.

FSN 1978 National Atlas; Federal Survey of Nigeria Press.

Henriet J P 1976 Direct application of the Dar Zarrouk parameters in groundwater surveys; Geophys. Prospect. 24 344-353.

Kelly W E 1976 Geoelectric sounding for delineating groundwater contamination; Groundwater 14 6-10. 
Mogaji K A, Adiat K A N and Oladapo M I 2007 Geoelectric investigation of the Dape Phase 111 Housing Estate FCT Abuja Northcentral Nigeria; J. Earth Sci. 1(2) $76-84$.

Naudet V, Revil A, Rizzo E, Bottero J Y and Begassat P 2004 Groundwater redox conditions and conductivity in a contaminant plume from geoelectrical investigations; Hydrol. Earth Sci. 8(1) 8-22.

Oladapo M I, Mohammed M Z, Adeoye O O and Adetola O O 2004 Geoelectric investigation of the Ondo-State Housing Corporation Estate IjapoAkure southwestern Nigeria; J. Mining Geol. 40(1) 41-48.

Oseji J O 2010 Geoelectrical investigation of groundwater resources and aquifer characteristics in Utagba-Ogbe Kingdom Nvokwa Land Delta State Nigeria; J. Env. Chemistry and Ecotoxicology 2(3) 38-46.
Rahaman M A 1989 Review of the basement geology of southwestern Nigeria; In: Geology of Nigeria, 2nd edn (ed.) Kogbe C A, Rock View Nigeria Limited.

Todd D K and Mays L W 2005 Groundwater Hydrology; John Wiley and Sons, New York.

Wightman W E, Jalinoos F, Sirles P and Hanna K 2003 Application of geophysical methods to highway related problems; Federal Highway Administration, Central Federal Lands Highway Division, Lakewood, Publication No. FHWA-IF-04-021.

Zohdy AA R and Martin R J 1993 A study of sea water intrusion using direct current sounding in the southern part of the Oxward Plain California; U.S. Geological Survey.

Zohdy A A R, Eaton G P and Mabey D R 1974. Application of surface geophysics to groundwater investigations; United State Geophysical Survey, Washington. 